\title{
ERNST BLOCH: ESPERANÇA POR UMA ALIANÇA ENTRE HISTÓRIA E NATUREZA ${ }^{1}$
}

\author{
Ernst Bloch: Hope for an alliance between history and nature
}

\author{
Ernst Bloch: Esperanza de una alianza entre \\ la historia y la naturalza
}

Wolfdietrich Schmied-Kowarzik ${ }^{2}$

Tradução: Rosalvo Schütz ${ }^{3}$.

Ernst Bloch certamente pertence ao rol dos grandes filósofos do nosso século. Está entre aqueles pensadores que impulsionam e levantam novas questões existenciais que se deslocam para o centro de nossa consciência. A questão que emerge na filosofia de Ernst Bloch, perpassando todas as suas

\footnotetext{
Título original: Ernst Bloch - Hoffnung auf eine Allianz von Geschichte und Natur. Publicado em: FLEGO, G.; SCHMIED-KOWARZIK, W. (Hg.). Ernst Bloch - utopische Ontologie. Band II des Bloch-Luckács-Symposiums 1985 in Dubrovnik. Bochum: Germinal-Verlag, 1986, S. 219237. E em: SCHMIED-KOWARZIK, W. Das dialektische Verhältnis des Menschen zur Natur. Philosophische Studien zu Marx und zum westlichen Marxismus. München: Karl Alber Verlag, 2018, S. 2002-2022. Tradução de Rosalvo Schütz, docente de filosofia na UNIOESTE, bolsista do CNPq e pós-doutorando no PPG-Filosofia da PUCRS.

2 Professor emérito de filosofia da Universidade de Kassel, Alemanha. Além de ter orientado diversos doutorandos brasileiros, vários trabalhos seus foram traduzidos no Brasil, sendo um dos mais recentes o livro A relação dialética do homem com a natureza. Estudos histórico-filosóficos sobre o problema da natureza em Karl Marx. Edunioeste, 2019. Atualmente vem publicando diversos estudos especialmente sobre questões ambientais e filosofia intercultural.

3 Doutor em Filosofia pela Universidade de Kassel, Alemanha. Docente de filosofia na Universidade Estadual do Oeste do Paraná (UNIOESTE). Bolsista de produtividade do CNPq e pós-doutorando no PPG-Filosofia - PUCRS. ORCID: http://orcid.org/oooo-0002-4548-6652. E-mail: rosalvoschutz@hotmail.com
} 
obras e que a todos atinge e diz respeito, é o problema existencial do futuro, com todos os seus aspectos e tons. Nossa vida não é um estado, mas um interminável progredir e modificar-se, e ela mesma está inserida em um processo social de devir, o qual nós chamamos de sociedade; esa, por sua vez, também está inclusa no processo relacional ainda mais amplo do devir cósmico. Mas nós não estamos entregues apaticamente a esse progredir interminável. Pelo contrário: nós entendemos esse processo vital mediante a nossa práxis vital inserida no presente e algo do passado permanece agindo em nosso recordar assim como o nosso esperançar nos impulsiona para o ainda excepcional.

Pensar e esclarecer essa perspectiva negligenciada pela filosofia precedente, rumo ao futuro, é a tarefa que Ernst Bloch persegue incansavelmente desde o Espírito da utopia (1918/23), passando pelo Princípio esperança (1954-59), até o último trabalho Experimentum mundi (1975), buscando transcrevê-la de modo cada vez mais elementar.

I.

A Introdução tübingueana à filosofia [Tübinger Einleitung in die Philosophie] inicia com as conhecidas palavras de Bloch: "Eu sou. Mas eu ainda não me tenho. Com isto primeiramente nós seremos" (1963, p. 13) ${ }^{4}$. O ponto de partida da filosofia de Bloch é o "eu sou", ou melhor, o "sou", esse existir in-pré-pensável que nós já desde sempre somos e do qual nunca podemos ser possuidores, pelo fato de, como existente, ele sempre preceder insondavelmente o pensar, sendo, mesmo assim, aquilo que nos impulsiona. Determiná-lo - o que implica também a nós mesmos - pensando e agindo para, assim, avançar no vir-a-ser, é tarefa de nosso filosofar. Esse "sou" não é apreensível, é o "obscuro do instante vivido", que acompanha todo o nosso ser próprio, inclusive impulsionando o seu progredir para adiante. "Não se pode sentir que se está vivo. O próprio

4 Quando disponíveis edições brasileiras, as referências são feitas em conformidade com elas ou são traduzidas diretamente, mantendo-se a referência da obra original citada. (N.T.) 
"quê" que nos estatui como vivos não assoma. Ele repousa bem fundo, lá onde começamos a ser corporais" (BLOCH, 2005, p. 49) 5 .

O que aqui nos incita primordialmente e impulsiona vividamente ainda não é o si mesmo, no qual nós tentamos nos ter, mas é o existente, o que instiga e impulsiona em nosso corpo vivo, sendo a "fome" aquilo com o que tudo se inicia. $O$ impulso, porém, de autopreservação do corpo, que se expressa pela fome, não permanece estarrecido - assim como todos os outros impulsos também não -, ele se modifica conforme o modo e os conteúdos com os quais é satisfeito: e isso não apenas na esfera da história de vida individual, mas também social, cultural e historicamente.

Assim, a autopreservação significa, em última instância, o apetite de proporcionar condições mais adequadas e apropriadas ao nosso si-mesmo a desdobrar-se, este si-mesmo que começa a se construir por meio da solidariedade e enquanto solidariedade. Instauradas as condições, por meio delas se prepara o encontro consigo mesmo (BLOCH, 2005, p. 72) .

E com isso já estamos no princípio esperança (SCHMIED-KOWARZIK, 1999), que nos fornece um objetivo de conteúdo para a nossa vida enquanto estivermos vivos. Essa esperança não é algo que nos advém de fora nem algo do qual podemos nos esquivar, mas é a orientação fundamental de nossa vida humana por uma existência plena, tanto para nós enquanto indivíduos quanto como humanidade. Lá onde a esperança individual ou mesmo aquela relacionada com os outros desmorona totalmente, aí o ser humano prefere a morte em vez de continuar vivendo. Nesse sentido, o princípio esperança é a esperança da nossa humanidade, que anseia por realização, orientada para frente e para dentro da história. "Por isso, a esperança, este afeto expectante contrário à angústia e ao medo, é a mais humana de todas

\footnotetext{
Compare ZIMMERMANN, 2001.

Compare SCHMIED-KOWARZIK, 1999.
} 
as emoções e acessivel apenas a seres humanos. Ela tem como referência, ao mesmo tempo, o horizonte mais amplo e mais claro" (BLOCH, 2005, p. 77)7.

É a partir da esperança de nosso existir que se formam os "sonhos diurnos. Eles sempre procedem de uma carência e querem se desfazer dela. Todos eles são sonhos de uma vida melhor" (BLOCH, 2005, p. 79) ${ }^{8}$. Mas eles não poderiam avançar se permanecessem sonhos e imagens de desejos de uma consciência não integrada no existente, ou se a realidade já estivesse pronta e acabada. Antes o contrário: nossa consciência antecipadora, que recorre ao "ainda não consciente" de si mesma, é parte de nossa existência viva que anseia por realização e, por isso, a conduz rumo a uma produtividade reveladora. Tudo isso, no entanto, apenas é possível porque o nosso próprio existir vivo é parte da realidade em existência, que é um processo totalmente inacabado. A essa realidade nós denominamos mundo e é nele que nós estamos inseridos, com nosso modo humano de existir e intervir produtivamente, enquanto um momento desse processo ainda aberto. Também a totalidade do processo do mundo tem um futuro que ainda não está totalmente determinado, nele ainda estão contidas latências e atuam tendências - sendo a história humana uma delas - as quais ainda não estão decididas em seu conjunto.

No mundo muita coisa ainda está inconclusa. Todavia, nada circularia interiormente se o exterior fosse totalmente estanque. Do lado de fora, porém, a vida é tão inconclusa como no eu que opera neste lado de fora. [...] O real é o processo e processo é a mediação vastamente ramificada entre o presente, o passado pendente e sobretudo o futuro possível (BLOCH, 2005, p. 194).

Aqui Bloch se vincula à filosofia da natureza, de Schelling e, com isso, ele é um dos poucos pensadores que não se deixa arrastar pelo espírito do seu

\footnotetext{
Compare LÖWY, 1997.

8 Compare SCHMIDT, 1988.
} 
tempo, pois há mais de 150 anos a filosofia não ousa mais pensar a natureza de modo filosófico, tendo deixado essa tarefa totalmente a cargo do acesso teórico e experimental possibilitado pelas ciências naturais. Pelo acesso delas, no entanto, a natureza é reduzida a uma estrutura de leis pelas quais - embora por seu intermédio tenha-se tornado possível colocar tecnicamente a natureza ao nosso dispor -, simultaneamente, somos furtados de todo impulso de vida próprio da natureza, com crescentes e devastadoras consequências para nós.

Schelling pensa a natureza de modo totalmente diverso e Bloch se liga completamente a ele: busca apreender a natureza a partir de suas próprias potências e de seu ser real-existencial ${ }^{9}$. Nós somos capacitados para tal, uma vez que nós mesmos estamos coenvolvidos existencialmente na natureza, de maneira que, com o nosso produzir propriamente humano, tomamos parte de modo específico no produzir da natureza. Nosso próprio ser real seria incompreensível, se não o pudéssemos compreender desde o ser real da própria natureza, pelo qual nós não apenas emergimos, mas o qual, além disso, continua agindo em nós mesmos. Ao se referir a Schelling, Bloch assim se expressa:

Quão diferentemente, no entanto, atua um sentir, que em seu intuir se volta totalmente para o externo. E não apenas intuitivamente, mas também participando vital e vigorosamente, para manter-se num pensamento que, de tão imbricado, permanece tão embebecido quanto o rio das coisas mesmas. Para isto o jovem Schelling forneceu as marcas adequadas [...]. Ele assentou a natureza, mesmo onde ela parecia estar totalmente paralisada, ou completamente quantificada, no fluir de sua vigorosidade, criatividade, e mesmo pré-corporeidade. Os primeiros escritos de Schelling (até 1800) ocupam-se exclusivamente com o (co)saber do criativo, deste caminho ativo em fermentação, que conduz

9 Compare SCHMIED-KOWARZIK, 1996; ZIMMERMANN, 1998. 
à matéria e que é simultaneamente o próprio caminho da mesma. Schelling quer fazer surgir a matéria uma vez mais, tanto para os olhos do leitor quanto no objeto mesmo, desde estas forças originalmente ativas da repulsão e da atração. Ele crê tornar 'a matéria evidente' (BLOCH, 1972, p. 216).

A filosofia da natureza há de entender a natureza desde as potências dinâmicas que lhe estão subjacentes, de tal forma que - e isso mesmo no caso da assim chamada natureza inorgânica - daí seja possível compreender como os organismos vivos puderam e podem se criar a partir de si mesmos. No organismo, a produtividade da natureza surge na forma estruturada de um produzir potencializado; na estrutura, de um produzir autorregulativo. No entanto, somente na consciência humana a natureza, a partir de si mesma, traz à tona uma potência - embora de modo não consciente onde não apenas o ser humano vem a si em uma relação autoconsciente consigo próprio enquanto indivíduo e enquanto comunidade cultural, mas onde também, pela primeira vez, surge uma estrutura a partir da própria natureza desde onde toda a natureza, no seu devir precedente, pode ser compreendida. "Com isso" - assim continua Bloch - se dá também

o conceito de uma matéria em ebulição e antes de tudo processual, que compreende estar se organizando fisicamente em direção à luz e organicamente em direção à consciência. $O$ jovem Schelling segue o caminho, infelizmente quase esquecido, deste conceito neo-epicuriano, que passa por Paracelso, e que é simultaneamente neo-alquímico; com a criança humana enquanto filha da matéria mesma, com a qual a matéria abre um olho para si, se reflete (1963, p. 203).

No que, no entanto, Bloch insiste ainda mais do que Schelling, é na ideia de que o conjunto desse processo da natureza, enquanto um existir e devir criativo, de modo algum está encerrado, sendo ainda portador de possibilidades, latências e tendências que lhe emprestam um horizonte aberto de futuro. 
Estas cifras reais existem justamente porque o próprio processo do mundo é uma função utópica, tendo a matéria do objetivamente possível como substância. Neste contexto, a função utópica do planejamento e da transformação humanamente conscientes representa apenas o posto mais avançado, mais ativo da função auroral que ronda pelo mundo: do dia noturno em que todas as cifras reais, isto é, todas as formas processuais ainda estão em andamento e se encontram (BLOCH, 2005, p. 176).

Com isso, novamente se volta a indicar em direção a nós humanos, no entanto, não em direção ao "eu” existencial de cada individualidade, mas em direção ao "nós" da práxis histórico-social. Afinal, é justamente pela potência da consciência que os seres humanos estão em condições não apenas de reconhecer o mundo enquanto um processo no qual eles mesmos estão inseridos, mas também de - conforme as suas forças produtivas historicamente ampliadas - intervir conscientemente na sua mudança.

O homem é alguém que ainda tem muito pela frente. No seu trabalho e através dele, ele é constantemente remodelado. Ele está constantemente à frente, topando com limites que então já não são mais limites; tomando consciência deles, ele os ultrapassa. O propriamente dito no ser humano como no mundo ainda está por acontecer, está na expectativa, encontra-se sob o medo de ser frustrado, na esperança de ser bem-sucedido, pois aquilo que é possível pode tanto se tornar um nada quanto um ser: o possível, não sendo totalmente condicionado, é o não consumado (BLOCH, 2005, p. 244).

Justamente porque o que está por vir ainda não está decidido, mas está inserido em um momento de coparticipação humana daquilo que está ao seu alcance, Bloch pôde definir o "ser humano trabalhador" criativamente ativo, que trabalha por um mundo melhor, como sendo propriamente o "ponto 
arquimédico". Com isso certamente Bloch não se refere aos indivíduos isolados, mas aos seres humanos solidários que cooperam rumo ao objetivo comum de um futuro melhor. Essses, porém, certamente também não podem produzir o mundo de modo arbitrário, e sim apenas em conformidade com as suas próprias potências: as forças humanas produtivas historicamente reveladas.

O homem e seu trabalho tornam-se, desse modo, elementos decisivos no processo histórico do mundo; sendo o trabalho um instrumento de humanização mesma; sendo as revoluções parteiras da sociedade vindoura, da qual a atual está grávida; [...] [ele está] na linha de frente do processo do mundo, onde são tomadas as decisões, onde se descortinam novos horizontes. E o processo em direção a este futuro é unicamente o da matéria, que se condensa e atinge sua finalização no homem como sua flor mais vistosa (BLOCH, 2005, p. 244).

II.

Com nenhum outro filósofo, Ernst Bloch se confrontou de modo tão intenso quanto com Hegel. Ninguém o admira mais do que ele - talvez com exceção de Marx - e, no entanto, de nenhuma outra abordagem teórica ele quer ter o seu pensar tão decididamente diferenciado quanto da de Hegel. Uma de suas principais obras filosóficas - Sujeito-Objeto - é totalmente dedicada ao confronto com Hegel. Mas também o capítulo fundamental "A consciência antecipadora", da sua obra principal O princípio esperança, quer abrir uma contraperspectiva à Fenomenologia do espírito de Hegel. E os seus três escritos sistemáticos: $O$ problema do materialismo, Direito natural e dignidade humana e Experimentum mundi são como que uma contraposição à filosofia da natureza, à filosofia social e à teoria lógica das categorias - em uma consciente inversão da sua sequência em Hegel. 
Para Bloch, a filosofia de Hegel, em seu conjunto, é uma filosofia-processo, mas uma filosofia-processo na qual o processo já está encerrado e conceitualmente decidido de modo prévio, de tal forma que a filosofia, por isso, pode apenas reconstruí-lo posteriormente. Enquanto isso, para Bloch, trata-se de um pensar que há de se tentar compreender desde o processo, em meio a ele e mesmo enquanto aquilo que o faz avançar.

Por isso Bloch critica - em uma expressa conexão com o Schelling tardio - que Hegel inicie o seu sistema com a lógica ${ }^{10}$. Afinal, se a lógica - como em Hegel -, enquanto movimento das categorias do puro pensamento, nas quais tudo o que é já está compreendido, já está sobreposta à filosofia da natureza e à do espírito, então compreende-se por si que essas sobreposições categoriais não deixam espaço algum para o devir do novo nos reais processos da natureza e da história: estas já são sempre concebidas como acabadas, antes mesmo que sejam pensadas em sua processualidade. Daí a razão por que Bloch orienta a teoria das categorias, em Experimentum mundi, pelas reflexões feitas em suas filosofias da natureza e social e, também, não concebe a sua teoria das categorias enquanto conceito do ser, uma vez que tal conceito fixaria o que, uma vez sendo processo, ainda está em aberto. Muito mais do que isso, Bloch busca determinar as categorias enquanto formas de explicação de um pensar que compreende a si mesmo enquanto momento de um processo aberto em devir; assim também a teoria das categorias é finalizada com o item "Realização: teoria - práxis" (BLOCH, 1975, p. 239).

Para Bloch, a sistemática filosófica se inicia - e também aqui se percebe uma grande afinidade com Schelling - com a problemática natural-filosófica da produtividade ainda inacabada da natureza ou da matéria ainda em devir (O problema do materialismo). Também Hegel - instigado por Schelling faz preceder a sua filosofia do espírito de uma filosofia da natureza, o que Bloch leva em alta conta, pois aqui a natureza é - embora não tão dinâmica como em Schelling - compreendida enquanto "história do desenvolvimento

10 Compare SCHMIED-KOWARZIK, 2015. 
dialético rumo ao humano" (BLOCH, 1962/1977, p. 207). Mas em Hegel em contraposição a Schelling -, com o surgimento do mundo do espírito, a natureza em seu devir passou e acabou. Ela é apenas base, matéria e material à disposição do devir histórico dos humanos. Bloch cita uma frase de Hegel que representa uma atitude totalmente contrária à sua em relação ao cosmos:

\begin{abstract}
"A essência do universo, a princípio oculta e encerrada, não dispõe de força capaz de resistir à tentativa de quem pretende conhecê-la; acaba sempre por se desvendar e patentear sua riqueza e profundidade para que o homem dela desfrute" (HEGEL, 1985, p. 318).
\end{abstract}

Contra isso Bloch responde decididamente:

Bem ao contrário disso, o condutor do processo se chama Matéria e de forma alguma é um ser que por si só já une o sujeito com o objeto - como a chamada ideia universal, a não ser em decorrência de trabalho duro, aguçado precisamente com o esforço exigido pela resistência. A natureza ainda fechada do universo dificilmente pode ser refletida ou declarada como algo já pronto, ou até como algo efusivamente claro como a luz do sol, uma vez que, justamente como matéria, ela ainda se encontra em processo inconclusivo de suas objetivações. [...] O próprio mistério do universo não se encontra em algum tipo de depósito de lixo cosmo-analítico, mas no horizonte do futuro a ser conquistado (2005, p. 131).

De fato, apenas a filosofia do espírito de Hegel, e aqui mais uma vez especificamente a filosofia social e histórica, preenchem os critérios de uma filosofia-processo. Mas também aqui Hegel "contorna" - conforme critica Bloch - "o devir do futuro, pelo fato de não poder ser conhecido como é o passado lembrável e observável" (1962, p. 277). O próprio Hegel sempre de novo enfatiza que a filosofia só pode conhecer o processo na medida em que 
esse já tenha passado e que a sua tarefa é justificá-lo enquanto tal. A essa compreensão de filosofia, enquanto simples compreender em retrospecto de um processo já acabado, Bloch contrapõe toda a sua obra - e é aqui que evoca Marx enquanto testemunho - como pode ser especialmente verificado no capítulo sobre "A transformação do mundo ou as Onze teses de Marx sobre Feuerbach" (2005, p. 246) no Princípio esperança"1.

Sob a expressão-chave, "[...] associar o saber não só com o passado, mas essencialmente também com o que está por vir", Bloch continua:

O presente governa juntamente com o horizonte presente nele, que é o horizonte do futuro, e que dá ao fluxo do presente seu espaço específico, o espaço de um presente novo, melhor de manejar. Portanto, a insipiente filosofia da revolução, isto é, a modificabilidade no sentido do bem, foi inaugurada em última instância no horizonte do futuro e dentro dele, tendo ciência do novo e força para o seu direcionamento.

[...] Somente o horizonte do futuro, da maneira como o marxismo o obtém, tendo como átrio o passado, confere à realidade a sua dimensão real (2005, p. 278-279; 281).

Porém, toda a agudeza da contraposição entre Hegel e o marxismo, na forma como Bloch a representa, somente se torna clara lá onde nós consideramos o conjunto da história humana em vista de sua possível finalidade. Essa questão, aliás, é uma que move o filosofar de Bloch desde o início. Assim, mesmo o último capítulo do Espírito da utopia já é denominado “Karl Marx, a morte e o apocalipse" (1964, p. 289).

Tentemos, no entanto, primeiramente fazer um esboço da concepção hegeliana da história mundial. É conhecido que Hegel determina esperançosamente a história mundial como o "longo e duro trabalho" do espírito rumo ao "progresso na consciência da liberdade" (HEGEL, 1979, p. 32).

1 Compare SCHMIED-KOWARZIK, 2014. 
Esse "progresso na consciência da liberdade", porém, na realidade não é produzido pelos indivíduos historicamente ativos ou pelos Estados individuais, mas se afirma "sobre as costas" das intenções dos seus agentes, enquanto "astúcia da razão", embora, mesmo assim, só progrida a partir das ações e decisões individuais destes.

Por isso, para Hegel, é impossível agir rumo a um objetivo histórico mundial. Para ele, a mais alta identificação do indivíduo ativo é com o seu povo e com o seu Estado; mas também os Estados podem entender-se apenas na sua própria eticidade e se afirmar para fora na medida em que se confrontam com outros Estados, sem possibilidade de uma influência intencional sobre a história mundial. Por outro lado, a história mundial executa implacavelmente o seu julgamento - como afirma Hegel - sobre as ações dos indivíduos e dos Estados, por intermédio daquilo que decorre do processo indicado. $\mathrm{E}$ a filosofia apenas há de apreender esse julgamento posteriormente, a partir daquilo que a história mesma já realizou, desde as consequências históricas, desde a ascensão e queda dos Estados e de sua constituição ética ${ }^{12}$.

Bloch, portanto, de modo algum se contrapõe à filosofia histórica de Hegel na medida em que, segundo essa, a história mundial seria o progredir astucioso do tornar-se consciente e da realização da liberdade; pelo contrário: é justamente isso que explicita o "princípio esperança" como motivação impulsionadora em nós e no processo da história. Contra o que Bloch se volta é que, segundo Hegel, a história mundial e o seu julgamento mundial sempre permanecem apenas como destino para os indivíduos ativos e de que se trataria apenas de uma "realização do espírito geral" a ser apreendido pela filosofia e não de um progresso na consciência histórico-mundial e no agir social dos indivíduos. E é aqui que Bloch vê a contribuição decisiva da filosofia crítico-revolucionária de Marx, a qual não apenas desvenda a astúcia da razão histórico-mundial enquanto história da produção social, mas, para além disso, convoca, por meio de sua abordagem filosófica, os seres humanos para a tarefa e responsabilidade da práxis histórico-mundial.

12 Compare SCHMIED-KOWARZIK, 1999. 
Marx se apropria mutatis mutandis da mesma (da teoria hegeliana da astúcia da razão - W.S.-K.), mas a põe, do mesmo modo como na dialética, sobre pés materiais. A astúcia da razão se torna aqui concreta como sendo o poder do processo de produção que sempre de novo prevalece: para a dialética materialista este é o verdadeiro condutor da história até o presente, é o "destino" até agora inescrutável. [...] É nesta dialética que vive, por detrás das costas dos indivíduos e de sua consciência imediata, pois, o real-vivo da filosofia da história hegeliana. Tanto a astúcia da razão quanto especificamente a liberdade, que enfim se afirma na mesma [...]. 'Progresso na consciência' é o crescente estar junto dos seres humanos na criação da história como sendo sua, feita por eles, compreendida e própria (BLOCH, 1962, p. 236).

Aqui fica claro que, para Bloch, a história mundial sempre foi e sempre será um avançar rumo à libertação, e nisso ele sabe que está de acordo com Hegel. Mas, uma vez que compreendemos a história mundial como esse processo mediado por nós mesmos, não a podemos mais abandonar a si mesma, pois somos chamados a atuar rumo a esse objetivo de libertação, solidariedade entre os seres humanos e a aliança com a natureza em escala histórico-mundial.

O acontecimento não está encerrado, pois ele próprio é um constante para diante no mundo que implica sorte passível de mudança. Assim, a totalidade das Onze teses anuncia: a humanidade socializada, aliada a uma natureza mediada por ela, significa a reconstrução do mundo como pátria ou lar (Heimat) (BLOCH, 2005, p. 282).

Acertadamente aqui, onde a totalidade da história humana é considerada enquanto processo aberto, a natureza ressurge no horizonte da análise do problema, pois a história humana como um todo está inserida no processo inconcluso da natureza. A história não poderia ser uma 
reconstrução transformadora do mundo se a "natureza" não tivesse liberado em nós forças produtivas para a consciente transformação; mas a reconstrução consciente de nosso mundo rumo à paz, em direção à qual o processo do devir do mundo já sempre instiga, só pode dar certo por meio das nossas próprias forças produtivas historicamente formadas. Este é o núcleo mais profundo da ontologia do ainda-não-ser blochiana:

Sem a matéria não há solo para a antecipação (real); sem antecipação (real) não há horizonte concebivel para a matéria. Desse modo, a possibilidade real não reside numa ontologia acabada do ser do que existiu até o momento, mas na ontologia, a ser renovadamente fundada, do ser do ainda-não-existente, que descobre o futuro até mesmo no passado e na natureza como um todo (BLOCH, 2005, p. 234).

Bloch é o primeiro pensador que, recorrendo a Schelling e Marx, levanta e enfrenta teoricamente o problema da aliança entre homem e natureza - especialmente no capítulo sobre "Vontade e natureza" no Princípio esperança (2006, p. 179), e isso bem antes da eclosão generalizada do debate sobre a crise ambiental.

Assim como lá onde a história ainda não é compreendida como sendo trabalho comum rumo a uma sociedade solidária tornam-se dominantes relações de produção que oprimem e exploram os seres humanos trabaIhadores e, com isso, atravancam o caminho do progresso do processo histórico, assim também lá onde nós não mais ou ainda não compreendemos a natureza enquanto processo em devir, a natureza é tratada como um material que pode ser manipulado e explorado arbitrariamente. Mas essa crescente alienação dos seres humanos em relação à sua base natural viva na qual eles mesmos estão inseridos, por fim, volta-se contra eles mesmos: a história humana não pode se afirmar contra os processos naturais que a tudo envolvem, mas somente, na medida das possibilidades da práxis humana, realizar-se em aliança com a natureza; o fim último da história e 
do processo natural é, pois - como formula Bloch em continuidade com o Jovem Marx -, "naturalização do homem e humanização da natureza".

De igual modo: no lugar do técnico como mero enganador ardiloso ou como espoliador, encontra-se concretamente o sujeito mediado socialmente consigo próprio e que de forma crescente se medeia como o problema do sujeito na natureza. Assim como o marxismo descobriu no ser humano trabalhador o sujeito da história que se produz no real, assim como somente pode ser plenamente descoberto e desenvolvido no socialismo, assim é provável que na tecnologia o marxismo também avance até o sujeito desconhecido, em si mesmo ainda não manifesto, de processos naturais: mediando as pessoas consigo, a si mesmo com as pessoas, e a si próprio (BLOCH, 2006, p. 228).

Bloch destaca que, em nosso século, a ciência natural e a técnica avançaram com passos de gigantes: teoria quântica e tecnologia das irradiações, por exemplo, aproximam-se das forças produtivas subatômicas que constituem o nosso universo. No entanto, elas avançam em suas fronteiras teóricas e práticas sem saber com o que de fato têm a ver e, por isso, sem de fato poder exercer o controle responsável sobre o seu agir. Na moderna técnica e ciência natural se mostra, de forma crescente, uma contradição interna: por um lado, elas adentram cada vez mais nos mais íntimos segredos da natureza - de certo modo realizando os sonhos mais ousados da magia e da alquimia do século passado -; por outro lado, no entanto, ciência e técnica se distanciaram de modo vitalmente ameaçador dos seres humanos e da natureza: elas se alienaram destes.

A contradição da moderna ciência e técnica em relação às interconexões vitais humanas e naturais se amplia cada vez mais e, nos acidentes técnicos, se revela, de modo cada vez mais agigantado, a sua extensão; cada vez mais a conexão entre o desenvolvimento científico-tecnológico com as necessidades humanas e os circuitos vitais da natureza vem sendo perdida. 
Se quisermos nos livrar da presente estrutura alienada de nosso "progresso" sem consciência, que simultaneamente é também regresso, então precisamos de uma inversão = revolução fundamental também de nosso pensamento científico e do nosso agir técnico. As possibilidades para tal estão absolutamente dadas e chegam mesmo a transparecer, ainda que não conscientemente, em algumas experiências-limite das próprias ciências naturais e na técnica.

Para conseguirmos alguns pontos de conexão em nosso pensamento para uma inversão, inicialmente precisamos nos conscientizar mais fortemente do nosso próprio ser-natureza inserido no conjunto das relações vitais e produtivas. Esse primeiro passo Bloch aborda na seção "O elétron do sujeito humano, da tecnologia da vontade" (2006, p. 228), onde primeiramente lembra técnicas de domínio da consciência e do corpo do leste asiático, mas também o pensador e médico da renascença Paracelso. Em nossa tradição europeia, justamente a concentração exclusiva nas ciências racionais e na dominação da natureza externa definhou ou até mesmo encobriu totalmente a via de acesso à natureza em nós.

De que na matéria humana exista uma potência dormente que não tem noção de suas próprias forças, que na verdade se manifesta em milhares de experiências não regulamentadas, porém sem uma única teoria adequada. Há futuro em tudo isso, um problema legítimo do futuro, e há de fato um enorme receptáculo de energia que paira sobre o cume da nossa consciência. [...] O campo de atuação possível do ser humano na natureza é definitivamente mais espaçoso, menos limitado. E pode sê-lo - com o que retorna ao tema principal - em virtude daquele possível sujeito da natureza que se engendra e se dinamiza utopicamente não apenas de modo subjetivo, mas também objetivo (BLOCH, 2006, p. 239-240).

Mas esse modo de compreensão, que inviabiliza o acesso à nossa própria natureza, é apenas um modo de acessar a vivacidade da natureza. $\mathrm{O}$ outro 
caminho nos leva a compreender a natureza como um todo, para além da equivocada concepção que a reduz a um mecanismo regrado por leis, mas novamente enquanto uma - assim como na filosofia da natureza de Leibniz a Schelling - interconexão que se autoproduz. Isso Bloch discute na seção "Co-produtividade de um possível sujeito da natureza ou técnica da aliança" (BLOCH, 2006, p. 240). Por fim, é a própria natureza que produziu vida a partir de si mesma e, no interior da vida, também a consciência humana, a qual, por sua vez, está em condições de conhecer a natureza e de nela intervir consciente e produtivamente. Em nossa reconstrução puramente mecânica do mundo, nós negamos essa interconexão produtiva e, com isso, destruímos justamente as potências naturais da vida e da consciência.

Na realidade, porém, nem [a natureza] acabou de florescer nem a história humana com sua corporeidade, seu contexto e sobretudo com sua técnica, está ligada à natureza somente como a algo passado. Pelo contrário: a natureza definitivamente manifesta não se situa diferentemente da história definitivamente manifesta no horizonte do futuro, e somente neste convergem também as futuramente bem espectáveis categorias de mediação da técnica concreta. Quanto mais precisamente se tornar viável uma técnica da aliança em lugar da externa, uma mediada com a co-produtividade da natureza, tanto mais seguramente as forças construtivas de uma natureza congelada voltam a ser liberadas. A natureza não é fato passado, mas o canteiro de obras ainda não desocupado, o material de construção ainda não adequadamente existente destinado a edificar a casa humana ainda não adequadamente existente. [...] Por essa razão, é certo que a casa humana não apenas está situada na história e sobre o chão da atividade humana, como também se encontra sobretudo sobre o chão de um sujeito mediado da natureza e sobre o canteiro de obras da natureza (BLOCH, 2006, p. 244-245). 
III.

No contexto atual e depois de termos considerado a história e a natureza tanto a partir do seu estar separados quanto do seu estar juntos, indicando que também aqui cabe ao trabalho humano e à práxis a tarefa da mediação criadora, uma questão cada vez mais ameaçadora se impõe: de fato essa aliança pode dar certo? Ainda temos tempo de alcançá-la tendo em vista a rapidez com que a catástrofe se aproxima de nós?

Ernst Bloch contava com uma rápida expansão do socialismo depois da II Guerra Mundial e esperava, acima de tudo, que houvesse uma mudança interna da sociedade socialista em direção a uma nova e concreta concepção de "técnica sem violentar". Ambas as coisas não aconteceram. Em vez disso, se consolidou mundialmente - e de modo cada vez mais rápido - o desenvolvimento de um modo de produção industrial cujas consequências visíveis são cada vez mais assustadoras, uma vez que ameaçam os fundamentos de nossa vida assim como as de todas as formas de vida deste planeta. Nesse entremeio, a possibilidade de uma liquidação global se tornou uma tendência real em nossa história, e dela nunca mais desaparecerá13.

Uma guerra mundial, levando em conta o acúmulo de armamentos atômicos existente atualmente, pode ser tomada quase como sendo sinônimo de extermínio do nosso mundo. E ainda que os dois blocos de poder ${ }^{14}$ busquem se excluir desse extermínio mediante armamentos cada vez mais sofisticados, ainda assim, por meio dos sistemas armamentistas desenvolvidos e das tecnologias cada vez mais autorreguladoras, a autoaniquilação da humanidade, mesmo que involuntariamente, tornou-se, devido a uma possível falha técnica ou humana, infinitamente mais provável do que a sua sobrevivência planejada.

Junto a Ernst Bloch, e quase simultaneamente, também Martin Heidegger se colocou esse problema da nossa relação científico-tecnológica com a natureza e dos perigos aí implicados. As preleções sobre o assunto foram

\footnotetext{
13 Compare ANDERS, 1972.

14 Lembrando que o texto foi escrito quando a chamada Guerra Fria ainda estava em andamento. Daí a menção aos "dois blocos de poder". (N.T.)
} 
publicadas no livreto A técnica e a virada (Die Technik und die Kehre) (1962) Tanto Bloch quanto Heidegger referem-se a um verso de Hölderlin de seu hino Patmos: "Onde há perigo cresce também o que salva" (HÖLDERLIN,1998, p. 447). Será que, para nós, hoje ainda pode crescer alguma esperança e força salvadora desde o pensamento contido nessas palavras de Hölderlin?

Martin Heidegger define a técnica, no seu atual desenvolvimento, enquanto um perigo para os seres humanos e não apenas para eles - e o "mais perigoso do perigo" consiste no fato de que ele nos permanece oculto, pois distorce nosso olhar em relação ao ameaçador, uma vez que "sempre ainda e sempre de novo" - como diz Heidegger - parece "como se a técnica fosse um meio nas mãos do homem" e pudesse estar à sua disposição conforme sua vontade e fins arbitrariamente estabelecidos. "Na verdade agora a essência do homem lhes é indicada como sendo o andar de mãos dadas com a essência da técnica" (HEIDEGGER, 1962, p. 37), pois a essência da técnica - portanto não a sua estrutura técnica atual - é evidenciar e desvelar as possibilidades do ser.

$\mathrm{Na}$ atual aplicação e autocompreensão da técnica e de todo o seu mecanismo, o qual Heidegger denomina "armação", há, portanto, uma inversão fundamental. "Isso quer dizer que o ser humano está entregue impotentemente ao prosperar e ao arruinar da natureza? Não. Isso quer dizer o puro oposto" (1962, p. 45), pois a "armação", a técnica, "embora encoberta, ainda é olhar, [e] não uma habilidade cega, no sentido de uma fatalidade completamente envolta" (1962, p. 45).

Daí, portanto, há de se esperar por uma "virada". Mas a "virada" não é algo que nós podemos realizar tecnicamente, ou que possamos realizar arbitrariamente pela autoglorificação humana. Para que a mudança da técnica ocorra, não podemos nos conceber tecnicamente enquanto serventes cegos dela, mas sim como seres humanos cientes do ser e da nossa inserção nele, que reflitam sobre o essencial de sua existência, que percebam "que todo o simples querer e fazer segundo o modo constituído (a técnica) insiste no desamparo" (HEIDEGGER, 1962, p. 45). 
Para possibilitar a virada, são exigidos seres humanos que "recusem" o mecanismo, que consigam estancar em si o devir do mecanismo, que tenham consciência de sua essência e tentem corresponder à reivindicação do ser.

Tudo isso, no entanto, nós só podemos se, diante da pergunta que nos aparece como sendo a mais próxima e urgente, "O que devemos fazer?", passarmos a refletir sobre "Como nós devemos pensar?", pois pensar é propriamente o agir, se agir significa ir ao encontro da essência do ser. [...] Apenas pensando nós aprendemos o morar naquela área na qual [...] ocorre o uso da armação (técnica) (HEIDEGGER, 1962, p. 40).

Com isso fica claro que uma mudança na técnica, que se contraponha ao perigo a ela inerente, que é um perigo inerente ao próprio ser do humano, não pode ser realizada por um simples querer e fazer técnicos, mas sim mediante uma "virada de si" do próprio homem, que busque "corresponder ao ser e às suas reivindicações e neste corresponder pertencer ao ser". Essa "virada de si", no entanto, não é em si um ato da vontade racionalmente impulsionado, mas acontece "como um lampejo", onde primeiramente o "perigo [,] enquanto perigo que de fato é, se nos mostra propriamente" (HEIDEGGER, 1962, p. 40). Com isso fica claro aquilo que Heidegger busca abordar por meio do verso de Hölderlin.

Onde está o perigo enquanto perigo, já prospera também o que salva. Mas estes não se põem lado a lado. $O$ que salva não está ao lado do perigo. O perigo mesmo já é, quando ele é enquanto o perigo, o que salva. O perigo é o que salva na medida em que traz à tona, a partir de sua essência invertida e ocultada, aquilo que salva. O que significa 'salvar'? Quer dizer: resolver, libertar, livrar, proteger, recuperar, tomar na mão, apoiar (HEIDEGGER, 1962, p. 41). 
A virada é algo que precisa acontecer em nós, no entanto, não criada por uma decisão racional e um ato planejado da vontade, mas como algo que cresce no ser humano pensante na medida em que o perigo se lhe torna mais visível.

Talvez nós estejamos postos nas sombras projetadas para adiante da chegada dessa virada. Quando e como ela habilmente ocorrerá ninguém sabe. Também não é necessário saber isso. Um saber desse tipo seria o mais prejudicial para o ser humano, porque a sua essência é ser aquele que espera, que espera pela essência do ser, na medida em que pensando o guarda (HEIDEGGER, 1962, p. 41).

Portanto, se o ser humano, em sua essência, "renunciar à obstinação humana" tornando-se o "pastor do ser", ele corresponderá ao apelo do "ser" (1962, p. 41).

A esse olhar retrospectivo de um pensar e esperar pelo ser, Ernst Bloch contrapõe o seu conceito de princípio esperança.

\footnotetext{
'Onde há perigo cresce também o que salva': Este verso de Hölderlin indica o dialético-positivo momento da guinada em que desaparece o medo do lugar da morte. [...] Perigo e fé são a verdade da esperança, de tal modo que ambos estão reunidos nela e o perigo não contém medo, nem a fé tem em si uma quietude indolente. Desse modo, a esperança é, em última análise, um afeto prático, militante. Ela desfralda bandeiras (2005, p. 113-114).
}

Diferentemente de Heidegger, a autovirada em vista do perigo não permanece no recusar-se a si mesmo frente ao mecanismo, ligando-se ao ser de modo pensante para, a partir daí, esperar pelo que salva. Para Bloch, diante do perigo, cresce em nós uma esperança prática e militante, que nos instiga para uma práxis revolucionária consciente e conjunta. A práxis revolucionária 
não é algo técnico nem recusa o mecanismo que faz dos seres humanos um apêndice de um desenvolvimento automatizado: ela é mais do que um pensar voltado para a essência do ser e, antes, a tentativa prática e conjunta de modificação das atuais relações dos seres humanos entre si e com a natureza.

A crença e a base possibilitadora dessa esperança prática, por um lado, surge e está em nós mesmos, pois em nós mesmos ainda há - apesar das relações deformadoras do nosso agir e pensar - muitos "sonhos para a frente", o que nos impulsiona para além do mal existente. "Imaginar-se rumando para o melhor sucede, num primeiro momento, apenas interiormente. É um indicativo de quanta juventude reside no ser humano, quanta coisa há nele a esperar" (BLOCH, 2005, p. 194) por ser realizado. Por outro lado, o mundo não é - tanto o natural quanto o social - algo já terminado e já predeterminado de antemão em seu processo de desenvolvimento. Muito antes, ele está cheio de potências - latências e tendências - que aguardam pela realização reveladora da práxis humana.

Ainda não está decidido o que há de emergir: aquilo que agora é pântano pode ser drenado. Redobrando-se a coragem e o saber, o futuro não virá como fatalidade sobre o ser humano, mas o ser humano virá sobre o futuro e ingressará nele com o que é seu (BLOCH, 2005, p. 196) 15 .

Pelo exposto até aqui apenas se fundamentou a ancoragem do esperançar naquilo que há de possível existente em nós e no processo mundial, do qual nós somos uma parte. No entanto, isso, de modo algum, já pode nos dar a certeza de que a realização de um futuro melhor, apesar das relações existentes e dos mecanismos de desenvolvimento instituídos, seja algo possível de ser alcançado.

E é justamente nisso que havemos de ver o perigo inerente à possibilidade de relegarmos o processo histórico apenas ao mecanismo do atual

15 Compare SONNEMANN, 1969. 
desenvolvimento, pois, se assim for, certamente o futuro advirá sobre nós enquanto uma realidade catastrófica. Ademais, o "processo histórico [,] por seu conteúdo propulsor e originador ainda não realizado [,] trata-se de um processo ainda não definido [e] pode desembocar tanto no nada quanto no tudo, tanto no vazio total quanto no êxito total" (BLOCH, 2005, p. 192).

Por isso, o "ser humano trabalhador", o ser humano prático-revolucionário, ele mesmo, é o "ponto arquimédico" pelo qual a carência miserável pode ser revertida. Apenas pela práxis revolucionária daqueles que reconhecem o perigo e se contrapõem a ele pode surgir a esperança por uma sociedade mais humana e uma relação pacificada entre seres humanos e natureza. Ou seja, não é pelo abandono do mundo a si mesmo, ou seja, aos poderes dominantes deste, que se pode transformá-lo em algo melhor. Com o perigo cresce, na práxis revolucionária daqueles que reconhecem e se contrapõem ao perigo, aquilo que salva. "Através disso, [d]o estado adiantado do nada, irrompendo na história com força cada vez maior" enquanto uma possível liquidação do mundo, se "[...] concedeu à própria dialética rumo ao tudo um poder constitutivo. A utopia avança, tanto na vontade do sujeito quanto na tendência-latência do mundo em processo (BLOCH, 2005, p. 306).

De todo modo, enquanto vivermos e quisermos viver, não podemos erradicar a esperança em nós, e esta não é um esperançar por ajuda externa, mas pelas potências ainda não esgotadas em nós mesmos, mediadas com as possibilidades reais ainda não exauridas do processo natural e histórico. Entretanto, tendo em vista a crescente ameaça, o esperançar só não basta, ele precisa se tornar esperançar militante de um contramovimento revolucionário que se oponha à desgraça que nos ameaça.

Onde há perigo, aí cresce também aquilo que salva, esta é a melhor esperança, mas onde há o que salva, cresce também o perigo, isso pertence igualmente ao fim e é decisivo para a esperança testada, a qual, de modo algum, é garantida, mas, antes, militante [...]. O estar disponível daquilo que é adverso [...] é o que faz vir à tona exata e constantemente 
o que é prometeico-rebelde. Não há outro otimismo a não ser o militante e, correspondentemente, também não há um pessimismo tão suspeito e paralisante quanto o militante. Ademais o real contém em seu sentido a possibilidade do ser enquanto utopia, o qual evidentemente não existe, mas do qual há a pré-aparência (Vor-Schein) fundado e fundamentável e seu conceito utópico principal, tanto política quanto ética, estética e meta-religiosamente ( $\mathrm{BLOCH}, 1975$, p. 238).

Com isso Ernst Bloch mostra que onde cresce o perigo - de um absoluto nada da história humana - também pode crescer em nós mesmos a potência revolucionária para uma salvação. Ele indica, assim, a possibilidade de um tornar-se militante da esperança - agora, se nós a vamos realizar, é algo que depende de todos.

\section{Referências}

ANDERS, G. Endzeit und Zeitenende: Gedanken über die atomare Situation. München: C.H. Beck, 1972.

BLOCH, E. Das Materialismusproblem, seine Geschichte und Substanz. Frankfurt: Suhrkamp, 1972.

BLOCH, E. Experimentum mundi: Fragen, Kategorien des Herausbringens, Praxis. Frankfurt: Suhrkamp, 1975.

BLOCH, E. Geist der Utopie: Zweite Fassung. Frankfurt: Suhrkamp, 1964.

BLOCH, E. O princípio esperança. Tradução de Nélio Schneider. Rio de Janeiro: UERJ, 2005. v. 1.

BLOCH, E. O princípio esperança. Tradução de Werner Fuchs. Rio de Janeiro: UERJ, 2006. v. 2.

BLOCH, E. Subjekt-Objekt: Erläuterungen zu Hegel. Frankfurt: Suhrkamp, 1962. BLOCH, E. Tübinger Einleitung in die Philosophie. Frankfurt: Suhrkamp, 1963. (Gasamtausgabe, Bd. 13).

HEGEL, G. W. F. Introdução à história da filosofia. [Tradução de] A. Pinto de Carvalho, H. C. de Lima Vaz e Orlando Vitorino. São Paulo: Abril Cultural, 1985. 
HEGEL, G. W. F. Vorlesungen über die Philosophie der Geschichte. In: WERKE in 20 Bänden mit Registerband. Frankfurt: Suhrkamp, 1979. Bd. 12.

HEIDEGGER, M. Die Technik und die Kehre. Pfullingen: Günther Neske, 1962. HÖLDERLIN, F. Sämtliche Werke und Briefe in 3 Bänden. München: Verlag Carl Hanser, 1998.

LÖWY, M. Erlösung und Utopie: Jüdischer Messianismus und libertäres Denken. Berlin: Karin Kramer Verlag, 1997.

SCHMIDT, Burghart. Kritik der reinen Utopie: . Eine Sozialphilosophische Untersuchung. Stuttgart: Metzler, 1988.

SCHMIED-KOWARZIK, B. Suche nach uns selbst ins Utopische. In: SCHMIEDKOWARZIK, W. Denken aus geschichtlicher Verantwortung: Wegbahnungen zur praktischen Philosophie. Würzburg: Königshausen \& Neumann, 1999. https://doi.org/10.12697/spe.2015.8.2.08

SCHMIED-KOWARZIK, W. Das dialektische Verhältnis des Menschen zur Natur : Philosophische Studien zu Marx und zum westlichen Marxismus. Freiburg: Alber, 2018.

SCHMIED-KOWARZIK, W. Existenz denken: Schellings Philosophie von ihren Anfängen bis zum Spätwerk. München: Karl Alber Verlag, 2015. https://doi. org/10.3196/219458451669222

SCHMIED-KOWARZIK, W. Von der Wirklichen, von der seyenden Natur: Schellings Ringen um eine Naturphilosophie in Auseinandersetzung mit Kant, Fichte und Hegel. Stuttgart: Frommann-Holzboog, 1996. bd. 8. https://doi. org/10.1017/s0263523200005401

SCHMIED-KOWARZIK, W. Vom Sinn und Ende der Geschichte: Fragen an Hegel und Marx angesichts des Exterminalismus. In: SCHMIED-KOWARZIK, W. Hegel in der Kritik zwischen Schelling und Marx. Frankfurt: Peter Lang, 2014. (Hegeliana, bd. 24). https://doi.org/10.3196/219458451568359

SCHMIED-KOWARZIK, W. Wieder Barbarei und Apokalypse: . Zu Ernst Blochs Philosophie des aufrechten Gangs. In: SCHMIED-KOWARZIK, W. Bildung, Emanzipation und Sittlichkeit: . Philosophische und Pädagogische Klärungsversuche. Weinheim: Deutscher Studien Verlag, 1993. https://doi. org/10.1515/9783110944600.59

SONNEMANN, U. Negative Anthropologie: Vorstudien zur Sabotage des Schicksals. Hamburg: Rowohlt, 1969. 
ZIMMERMANN, R. Die Rekonstruktion von Raum, Zeit und Materie: Moderne Implikationen Schellingscher Naturphilosophie. Frankfurt: Peter Lang, 1998.

ZIMMERMANN, R. Subjekt und Existenz: Zur Systematik Blochscher Philosophie. Bodenheim: Philo Verlagsges, 2001.

\section{Endereço Postal}

\section{Rosalvo Schütz}

Rua da Faculdade, 645 -

Jd. Santa Maria - Toledo/PR -

Prédio da Filosofia - $2^{\circ}$ piso -

CEP: 85.903-000 - TOLEDO - PR. 